\title{
Patrimonio colectivo y cuidado participativo
}

\author{
Matilde González Méndez | arqueóloga \\ URL de la contribución <www.iaph.es/revistaph/index.php/revistaph/article/view/4568>
}

La riqueza patrimonial española resulta una gran herencia costosa de mantener. El informe sobre mecenazgo de Arostegui y Villarroya (2019) apunta que las administraciones públicas del sur de Europa dedican más gasto al patrimonio cultural que las del centro y norte, pero es insuficiente. Más allá de considerar acciones poco planificadas, realizadas al calor de nuestras principales industrias (construcción y turismo) y alimentadas con fondos europeos, lo cierto es que, con una crisis irresuelta, nuestro patrimonio padece gran falta de recursos.

Ya que el dinero público es de la ciudadanía, algo que no siempre interiorizamos, partimos de cierta corresponsabilidad en la atención al patrimonio, pero necesitamos explorar más formas de financiación que la pública. Conseguirlo beneficiaría el incremento de recursos y la diversificación de bienes y objetivos de inversión. Dado que las administraciones del Estado disponen el destino de los recursos, no siempre en el marco de una política cultural o bajo criterios técnicos, las decisiones de políticos sobre inversiones patrimoniales no tienen por qué ser más fundadas que las de patrocinadores o donantes ${ }^{1}$ que deciden cuidar un bien desde cualquier entidad ciudadana.

Nuestra ley de mecenazgo ofrece beneficios fiscales a la participación privada menores que otros países vecinos (AGEA, 2012), aunque la reforma de 2014 los ha mejorado, sobre todo para el micro-mecenazgo ${ }^{2}$. Los mayores incentivos son para donaciones a fundaciones o asociaciones declaradas de utilidad pública, lo que en ambos casos implica contar con objetivos y planes de acción bien definidos y cierta infraestructura de funcionamiento para atender, tanto a la misión patrimonial como a la gestión administrativa y legal.

Dejando al margen que sean los bienes o instituciones más conocidos los objetos preferentes de atención, las pequeñas asociaciones, no declaradas de utilidad pública, no pueden ofrecer iguales beneficios fiscales (las aportaciones a estas deducen un 10\%) resultando así menos atractivas a la donación.

Mientras se espera una nueva ley estatal de mecenazgo, se aprobaron tres autonómicas (navarra, valenciana y balear) muy diferentes en cuanto a ámbitos e iniciativas incentivadas y a la concepción del mecenazgo de la que parten (AROSTEGUI; VILLARROYA, 2019), lo que denota la carencia de una concepción clara y homogénea de las políticas públicas del Estado. No obstante, si se estudiase su efectividad, podrían servir para mejorar la futura ley estatal.

La alternativa del micromecenazgo, crowdfunding, a través de plataformas participativas, accesible a particulares u organizaciones (grandes o pequeñas), es aún poco utilizada. Arostegui y Villaroya apuntan que en España no hay datos de uso para el patrimonio cultural, pero un estudio de ámbito europeo muestra que los proyectos patrimoniales son menos del $1 \%$ de los lanzados a financiación participativa de plataformas, siendo Inglaterra y Francia donde más se usan.

Ejemplos de grandes instituciones que recurren al micromecenazgo son el Museo Thyssen-Bornemizsa, que desde una plataforma propia consiguió financiar la restauración de un Canaletto, o el Museo del Prado para adquirir un Simón Vouet. Aunque resulta más fácil para grandes organizaciones, que además pueden ofrecer los mayores beneficios fiscales, las pequeñas también tienen oportunidades en el micromecenazgo.

Un repaso informal de las principales plataformas francesa (Ulule) y española (Verkami), muestra más iniciativas patrimoniales (promovidas por asociaciones, museos o particulares) en la francesa que en Verkami. La Tahona Cultural, plataforma nacida en 2012 específi- 
a debate Patrocinio, mecenazgo, crowdfunding ¿compromiso social o marketing interesado?

| coordina Ana Isabel Velasco Rebollo

camente para proyectos culturales (Ulule y Verkami son genéricas para proyectos creativos, culturales y sociales) cesó actividad en 2014. Ese año, Hispania Nostra, asociación de defensa del patrimonio cultural y natural, dispuso una plataforma de financiación colaborativa.

Distintamente a Verkami o Ulule, donde solo los proyectos de organizaciones amparadas por la ley de mecenazgo pueden ofrecer el mayor beneficio fiscal, los proyectos lanzados desde Hispania Nostra, declarada de utilidad pública, lo brindan. No obstante, de los quince finalizados que muestra su web, sólo dos consiguieron la solicitada. Promovidos por vecinos de pueblos de la "España vacía", incluso la superaron.

El panorama del micromecenazgo no parece radiante; tiene que superar dificultades como el desconocimiento público de sus ventajas fiscales o de las plataformas colaborativas como herramienta, el hecho de que sirva fundamentalmente a acciones puntuales (aunque pueden planificarse proyectos a largo plazo con campañas sucesivas), etc. Sin embargo, nuestra falta de cultura en atención al patrimonio es una carencia. Sea porque a la ciudadanía le resulta menos interesante de lo que pensamos los profesionales, o porque no consideramos su mantenimiento como responsabilidad, en España nos sentimos menos implicados que otros países de nuestro entorno en la atención al patrimonio.

Con todo, creo que el micromecenazgo está repleto de futuro porque democratiza las decisiones en torno al patrimonio, nos involucra en la decisión de qué bienes intervenir con nuestro apoyo, aúna individualidades en torno a bienes comunes y genera comunidad. Así, sin que fuese pretexto para ignorar responsabilidades, las Administraciones deberían promoverlo creando cultura de corresponsabilidad en el cuidado del patrimonio.

El mutchfunding, financiación compartida entre aportaciones ciudadanas y otra organización, podría ser una fórmula que algunas administraciones ya están probando para proyectos sociales, empresariales o culturales. Ejemplo de los últimos es Meta, iniciativa de la Diputación
Foral de Guipúzcoa, que impulsa proyectos culturales aportando un euro por cada uno proveniente de la ciudadanía, desarrollado a través de la plataforma Goteo. Sistemas similares, que permitiesen la participación compartida público-privada en proyectos cuya utilidad y viabilidad fuese previamente evaluada por las instancias responsables de la tutela patrimonial, podrían fomentar el apoyo y la implicación ciudadana con el patrimonio.

Además del patrocinio y mecenazgo de grandes y pequeñas empresas, incorporar a la ciudadanía completaría el círculo virtuoso del cuidado patrimonial.

\section{NOTAS}

1. Algunos ejemplos citados en los medios de comunicación: <https://www.eldiario.es/cultura/politicas_culturales/museo-pais_0_319518510.html>, <https://www. Ine.es/cuencas/2016/10/21/alcalde-morcin-afirma-museo-quesos/2001242.html> o <https://www.diariosur. es/costadelsol/201701/07/edificio-museo-municipal-sigue-20170107013656-v.html> [Consulta: 09/10/2020].

2. Al permitir a particulares una deducción en el IRPF del $75 \%$ de los primeros $150 €$ donados y un $30 \%$ de la cantidad excedente.

\section{BIBLIOGRAFÍA}

- AGEA RODRíGUEZ, S. (2012) Ley de Mecenazgo y las fundaciones de investigación y ciencia. Lychnos. Cuadernos de la Fundación General CSIC [en línea], n. ${ }^{\circ}$ 10, septiembre $2012<$ <ttp://www.fgcsic.es/lychnos/es_ES/articulos/ley-demecenazgo-y-las-fundaciones-de-investigacion-y-ciencia> [Consulta: 12/12/2019]

- RUBiO AROSTEgUI E, J. A.; VILLARROYA PLANAS, A. (2019) El papel del mecenazgo en la política española. Propuestas para reconfigurar su papel en la crisis en las artes y la industria cultural [en línea]. [Madrid]: Ministerio de Cultura y Deporte (trabajo realizado por Fundación Alternativas para Unidad Cultura y Mecenazgo), marzo 2019 <http://www. culturaydeporte.gob.es/dam/jcr:fc0e64ed-7450-4878-a8540e39e52bfc75/papeldelmecenazgo.pdf> [Consulta: 14/12/2019] 